Nuntius Antiquus, Belo Horizonte, v. 11, n. 2, p. 99-119, 2015

\title{
Hesíodo y Jenofonte. Trabajo, virtud y progreso: los núcleos de problematización ${ }^{1}$
}

\section{Hesiod and Xenophon. Work, virtue and progress: the cores of questioning}

\author{
María Cecilia Colombani \\ Universidad de Morón \\ Universidad Nacional de Mar del Plata \\ mcolombani@fic.com.br
}

Resumen: El proyecto del presente trabajo consiste en relevar el perfil del hombre común presente en Trabajos y Días, a propósito de las marcas antropológicas que aparecen en el poema. La administración de la vida en torno a la administración del trabajo constituye el primer tema del trabajo y a él dedicaremos la primera parte del mismo. En segundo lugar nos proponemos trazar un arco de lectura entre Hesíodo y Jenofonte para ver cómo se vinculan en una serie de tópicos que demuestran la solidaridad entre ambos, a partir de la consideración del trabajo y de la agricultura como la base de la vida misma.

Palabras clave: Hesíodo; Jenofonte; vida; trabajo; agricultura; êthos.

Abstract: The project of the present work consists of relieving the profile of the common man that is present in Works and Days, regarding the anthropologic marks that appear in the poem. The administration of the life concerning the administration of the work constitutes the first theme

\footnotetext{
${ }^{1}$ El apartado referido a Hesíodo forma parte de mi tesis doctoral Una aproximación arqueológica al discurso hesiódico desde la lógica del linaje de próxima edición por EUDEM (Editorial de la Universidad Nacional de Mar del Plata). Se han hecho las adecuaciones pertinentes al presente trabajo.
} 
of the work and to it we will dedicate its first part. Secondly we propose to plan an arch of reading between Hesiod and Xenophon to see how they link themselves in a series of topics that demonstrate the solidarity between both, from the consideration of the work and of the agriculture as the basis of life itself.

Keywords: Hesiod; Xenophon; life; work; agriculture; ethos.

Recebido em 17 de agosto de 2015 Aprovado em 16 de novembro de 2015

"Pues una buena organización es lo mejor para los
hombres mortales y una mala organización lo peor". ${ }^{2}$

(Trabajos y dias, v. 471-472)

El proyecto del presente ensayo consiste en relevar el perfil del hombre común presente en Trabajos y Días, a propósito de las marcas antropológicas que aparecen en el poema. La administración de la vida en torno a la administración del trabajo como pieza fundamental de la empresa subjetivante significa considerar las huellas que determinan el horizonte de la vida cotidiana donde se inscribe la legalidad humana. Este constituye el primer propósito de la labor y a él dedicaremos la primera parte del mismo.

En segundo lugar nos proponemos trazar un arco de lectura entre Hesíodo y Jenofonte para ver cómo se vinculan en una serie de tópicos que demuestran la solidaridad entre ambos, a partir de la consideración del trabajo y de la agricultura como la base de la vida misma. Hay, en ambos, una consideración que a nuestro entender se inscribe en una perspectiva económica, aunque desde distintos andariveles. Quizá una cita de Claude Mossé resuma la perspectiva al marcar la tarea del historiador

que intenta situar al hombre griego en un contexto económico y descubrir, tras el homo politicus a los filósofos, y tras el homo oeconomicus al que producía, cambiaba, gestionaba o incluso especulaba con la

${ }^{2}$ Todas las traducciones de Hesíodo son de HESÍODO. Obras y fragmentos. Aurelio Pérez Jiménez (prologuista) y Alfonso Martínez Díez (traductor). Madrid: Gredos, 2000. 
intención, para unos, de acumular bienes y fortuna, y, para otros, de asegurarse el sustento cotidiano. ${ }^{3}$ (MOSSÉ, 1993, p. 35)

Nuestro trabajo se juega nítidamente entre las dos dimensiones. El reaseguro del sustento en la Beocia empobrecida de Hesíodo y en el proyecto de acumular y expandir la riqueza en el caso de Jenofonte.

En el caso de Hesíodo, abordaremos el tema desde una perspectiva antropológica para abordar algunos aspectos que van constituyendo el êthos en tanto forma de vida, y la presencia del discurso en la constitución de esa manera de vivir o actitud de vida. Proponemos pensar los alcances que toma la inquietud ético-social del trabajo en Hesíodo, a partir de considerar en Trabajos y días el protagonismo que el mismo toma, lo cual sugiere una intensa preocupación por el vínculo trabajo-êthos en tanto manera de vivir. ${ }^{4}$

Pretendemos problematizar algunos tópicos que hacen al modelo de hombre que Hesíodo propone, a partir de los consejos y las recomendaciones que despliega, a propósito de los ciclos estacionales para descubrir una preocupación por la administración del tiempo y del trabajo. La propuesta de esas recomendaciones, inscritas en el marco de su función didáctica, constituye un llamado al robustecimiento de un modo de racionalidad. La aceptación y el cumplimiento de la misma dan cuenta de la implementación del discurso didáctico como instrumento eficaz para la consumación de un modelo de bíos transido por la sophrosýne y la armonía como valores tutelares. Tal como describe C. Mossé,

En primer lugar, tenemos el gran poema de Hesíodo, Trabajos y Días, calendario religioso que a la vez que nos revela la gravísima crisis del mundo griego de finales del siglo VIII a. C., crisis precursora de las violentas luchas que marca la historia del siglo siguiente, no deja de describir la vida cotidiana del campesino beocio, las relaciones amistosas u hostiles que tenía con sus vecinos, y las distintas actividades que jalonaban el año. (MOSSÉ, 1993, p. 36)

\footnotetext{
${ }^{3}$ Trad. Pedro Bádenas de la Peña.

${ }^{4}$ Coincidimos con la postura de P. Judet de La Combe y A. Lernould (1996, p. 302), cuando sostienen que "le travail apparaît comme l'activité qui définit l'homme essentiellement". En efecto, la disimetría ontológica entre ambos planos hace que el trabajo se defina desde un registro que va más allá de su dimensión funcional.
} 
Los tópicos a considerar se inscriben en este horizonte que implica una cierta manera de vivir; nos referiremos al concepto de trabajo y su relación con el de bienestar, asociado a ciertos placeres propios del hombre común, a la noción de previsión, como idea rectora de una buena gestión de la vida, la idea de administración, como aquello que hace del hombre un buen conductor y finalmente la idea de relación, como aquello que pone en juego los vínculos entre ese hombre común con los criados y esclavos, para ver cómo se juegan las relaciones de mando y subordinación.

Nos mueve, pues, un interés muy particular: tratar de reconstruir, a partir del texto, las características de la vida cotidiana. Se trata de transitar la pequeña historia de ese hombre de campo para descubrir en esa cotidianeidad las huellas del êthos, las marcas de una vida que se juega en los límites que el trabajo impone como marca subjetivante por excelencia para, a su vez, descubrir las huellas de una incipiente preocupación por un modo de racionalidad.

El proemio al calendario del labrador impone ciertas pautas para lo que consideramos un modelo de vida confortable en medio de la fatiga y la dureza que el trabajo requiere: "Fabrícate en casa todos los utensilios necesarios, no sea que los pidas a otro, aquél te los niegue, y tú te encuentres sin medios en tanto que se pasa la estación y se pierde la labor" (Trabajos y dias, v. 407-410). Relevamos la idea de bienestar desde dos vertientes: en primer lugar la posesión de todo aquello que resulte necesario para obtener los elementos que brindan comodidad. En la medida en que buena parte de la vida pasa por la obtención del fruto que brinda la tierra, en una economía de matriz eminentemente agraria, la construcción de los utensilios es capital a la hora de poder sostener la vida con dignidad, sin privaciones. En segundo lugar, el bienestar pasa por la independencia que brinda tener lo propio. El peligro de la vida parasitaria, que pone al hombre en relación de subordinación con aquél de quien depende, es un tópico capital en Hesíodo. Si bien en este texto estamos proponiendo la relación con el confort, el tópico resuena en otros aspectos, tales como la virtud, la honra y la dignidad.

En otoño la recomendación es clara y se vincula con la previsión. Previsión y confort aúnan sus vínculos cuando Hesíodo recomienda: "Justamente entonces, corta madera recordando las faenas correspondientes a la estación" (Trabajos y días, v. 422). Se trata, pues, de un plexo de consejos tendientes a prever las necesidades de la labor 
futura; labor que, por otra parte, devuelve la satisfacción del sustento que, a su vez, reporta el confort necesario para la vida cotidiana.

Las recomendaciones de invierno enfatizan el confort corporal como preocupación dominante. Previsión en la medida en que se puede evitar la enfermedad que el frío con su dureza es capaz de ocasionar.

La hostilidad del clima implica, asimismo, el retorno a la casa cuando la faena culmina; la casa aparece, pues, como un espacio acogedor frente a la hostilidad del espacio exterior y, desde esa marca, un tópos de confort: "Anticípate a él y regresa a casa cuando termines el trabajo, no sea que algún día te cubra desde el cielo una nube sombría y deje húmedo tu cuerpo y empapados tus vestidos" (Trabajos y días, v. 555-556).

La primavera invita a podar las viñas como modo de prever las bondades del vino, elemento indispensable para la vida campesina. A su vez, es el momento de traer a casa el fruto para tener bastante sustento (Trabajos y dias, v. 576-577). El tópico es recurrente y se inscribe en el doble horizonte que venimos manejando. La previsión del alimento impacta directamente sobre la racionalidad ya que implica un gesto de prudencia y cálculo tendiente al justo almacenamiento de aquello que brinda, a su vez, confort.

El verano es también el momento de otra previsión clave: procurar estiércol y forraje para que los bueyes y los mulos lo tengan en abundancia. Considerando el papel de los animales en las faenas del campo, su sustento es clave para la previsión del circuito de trabajo.

El siguiente tópico que nos proponemos relevar se refiere a la relación entre el hombre común que hemos venido pintando y sus criados o esclavos. El tema resulta de interés porque evidencia la racionalidad del sistema de trabajo, que se perfila como un modelo de acción que obedece a reglas y funciones precisas en el marco de los ciclos estacionales, como soporte temporal de la administración del campo, los granos y la hacienda. Si pensamos el apartado en relación a los precedentes, la relación es nítida. Sólo desde la ajustada organización de la tarea, que implica necesariamente la gestión de los vínculos entre los actores intervinientes, es posible alcanzar el confort y la cuota de placer que constituyen la vida media del hombre simple, como recompensa, incluso, del trabajo realizado.

Proponemos entonces recorrer el ciclo estacional para detectar los vínculos que se establecen. Este es el punto de partida del orden y de allí en más la larga descripción de los trabajos de otoño, invierno, primavera y 
verano. Trabajos y días no es tanto un manual para el trabajador, sino una enseñanza acerca de los ciclos, del orden de la naturaleza; dice Nelson: "It is not how to farm, but what the cycle of the year, with its balance of good and evil, profit and risk, anxiety and relaxation, implies about the will of Zeus that Hesiod is teaching" (NELSON, 1996, p. 53). El calendario es él mismo un símbolo del orden, articulado en la noción de límite. Cada estación limita las labores a partir de sus notas específicas. La primera marca la encontramos en los trabajos de otoño, a propósito de quiénes deben conducir los bueyes aptos para la faena:

Que los siga un hombre fuerte de unos cuarenta años después de desayunar un pan cuarteado de ocho trozos, para que atento al trabajo abra recto el surco sin distraerse con los de su misma edad, sino con el alma puesta en el trabajo. Otro no más joven que éste es el mejor para volear las semillas y evitar su acumulación; pues un hombre más joven se queda embobado tras los de su misma edad. (Trabajos y dias, v. 441-447)

Se trata de dos jornaleros. Dos elementos resultan interesantes: la edad y la alimentación. La edad suele ser una preocupación dominante del señor de la casa ya que ha aparecido a propósito de la elección de la esposa. En este caso, la edad está asociada a la posibilidad de trabajo y a la concentración en el mismo. Esto habla de la inquietud por la eficacia y la gestión para obtener los mejores resultados. La edad está directamente relacionada con la mejor obtención de un determinado logro, de un prestigioso motivo de preocupación; por ello roza también el matrimonio ya que sabemos que un mal matrimonio lleva al hombre a la ruina, sobre todo a partir de la nefasta consideración de la mujer en el marco de los actores que habitan la obra hesiódica. El trabajo y el matrimonio constituyen entonces piezas claves del confort o de la desgracia de un hombre. En los versos seleccionados se deja ver una consideración negativa de la juventud como edad de cierta inmadurez. Aquí se produce una cuestión paradojal. La mujer sí conviene que sea joven porque su juventud facilita la maleabilidad de su carácter y la producción subjetiva por parte del esposo. En cambio, la juventud en el trabajo es posible signo de distracción y falta de idoneidad en la tarea. De todos modos, lo que nos importa es la previsión en las respectivas elecciones, lo cual marca un télos preciso: el éxito en el modelo. 
El otoño sigue mostrando su ritmo laboral y una nueva complementariedad en el trabajo colectivo: "Cuando ya se muestren a los mortales los primeros días de labranza, poned entonces manos a la obra, juntos los criados y tú, arando la tierra seca y húmeda en la época de la labranza y ganando tiempo muy de mañana, para que llenen los frutos tus campos" (Trabajos y días, v. 458-462). El trabajo colectivo no demuestra en este punto disimetría estatutaria alguna. El éxito medido en la abundancia del fruto como marca constante no conoce rangos en esta instancia puntual. La misma organización aparece en el verso 470, "detrás el pequeño esclavo dará trabajo enterrando las semillas con la azada" (Trabajos y días, v.). El trabajo obedece a una cierta legalidad indispensable para la buena organización, no sólo de la tarea, sino de la vida en su conjunto a partir de la estrecha vinculación entre los érga y el bios.

Los trabajos de invierno traen una función novedosa del hombre de campo frente a sus esclavos. Se trata de una función didáctica, de advertencia y consejo, equiparable a la propia función de Hesíodo de cara a los hombres dedicados al trabajo; "Advierte así a los esclavos cuando ya el verano esté a la mitad; $<$ No siempre será verano; procuraos cabañas $>$ " (Trabajos y días, v. 502-503). El consejo se inscribe, a nuestro entender, en el mismo proyecto de administración racional de la casa y la vida de todos los que la habitan. La función se vuelve imprescindible porque si el éxito depende de una organización que abraza distintos actores, nada puede ni debe quedar al azar en los juegos de inquietud y previsión.

El verano devuelve dos marcas afines a lo que venimos relevando, la primera, una vez más, vinculada al trabajo; la segunda, al descanso. Cuando aparezca Orión, entre las dos últimas semanas de junio y la primera de julio, los criados son los encargados de aventar el grano en una era redonda y aireada. A continuación, el acople de tareas: el señor debe distribuirlo bien en jarras y colocar todo el alimento dentro de la casa. Más tarde, el merecido descanso: "Luego, por fin, deja que los esclavos relajen sus piernas y suelta los bueyes" (Trabajos y días, v. 608 a). Perfecta distribución del ciclo de trabajo: fatiga y descanso como las dos instancias que complementan el dispositivo de las tareas. Perfecto modelo de racionalidad de una administración que procura no sólo las faenas pautadas conforme a un orden que la propia estación en su intrínseca legalidad impone, sino también el reposo reparador, clave, seguramente, de la posibilidad de un nuevo inicio en la tarea. 
Podemos indagar, pues, el modelo de vida del hombre común, el campesino al que Hesíodo dirige sus exhortaciones. Hemos escogido algunos tópicos y los hemos trabajado por pares de efectos didácticos porque, en realidad, constituyen un todo compacto que da cuenta de la preocupación hesiódica por pintar un determinado êthos. Nuestro proyecto se inscribe en un horizonte de corte antropológico, en el marco de una preocupación êthopoiética en tanto poíesis tendiente a configurar un modelo de êthos, transido por la sophrosýne como sustento de la inquietud por la administración del trabajo y, en su seno, de la vida como objeto de preocupación existencial. El hombre es más que las bestias precisamente porque es capaz de instalarse en el mundo desde el lugar del sentido, resignificando la mera naturaleza y humanizándola, esto es, inscribiendo un nombre humano en ella. Su posición consiste en ese tópos intermedio entre dioses y animales. ${ }^{5}$

\section{La administración de la casa. La administración del trabajo. Los cruces jenofonteos}

"Creo que estoy más que suficientemente convencido de que vivir de la agricultura es lo más noble, lo mejor y lo más agradable". ${ }^{6}$ (Económico, VI, 11)

A continuación pretendemos relevar algunos aspectos antropológicos en el Económico de Jenofonte, a los efectos de trazar un arco de lectura para ver los alcances de una preocupación por la administración de la casa y del trabajo que ha tenido en Hesíodo un antecedente interesante. En efecto, los capítulos que componen el Económico no reflejan exactamente las condiciones de vida del campesino ateniense; se trata, más bien, de la situación de un propietario de terreno fértil, tal como fue el propio Jenofonte. He aquí un primer punto de contacto ya que Hesíodo no representa al campesinado empobrecido de Beocia, sino a un pequeño poseedor de una parcela de tierra para su cultivo.

\footnotetext{
${ }^{5}$ Sobre este lugar intermedio, ver A. Neschke (1993, p. 478).

${ }^{6}$ Todas las traducciones de Jenofonte son de JENOFONTE. Recuerdos de Sócrates; Económico; Banquete; Apología de Sócrates. Introducciones, trad. y notas de Juan Zaragoza. Madrid: Gredos, 1993.
} 
Debemos partir de la consideración de la tierra en el mundo antiguo. Tal como sostiene Mossé:

Conviene desde luego repetirlo, hasta el punto que parece a priori paradójico: el mundo griego era un mundo de ciudades, donde la vida urbana ocupaba un lugar esencial, y sin embargo la agricultura constituía la primera actividad de la mayoría de los miembros de la comunidad cívica. Incluso en ciudades como Atenas, Corinto, Mileto o Siracusa, la tierra es la que ante todo aseguraba a cada uno sus medios de vida. El mundo griego de época arcaica y de época clásica es primero y por encima de todo un mundo de campesinos. (MOSSÉ, 1993, p. 36)

Como hemos podido comprobar, en el apartado anterior, la relación con el trabajo y con la agricultura en particular es un enclave antropológico de relevancia en la obra hesiódica. No sólo posee un matiz antropológico sino también ético ya que el trabajo constituye una bisagra de la constitución del hombre prudente que encuentra en la dimensión del mismo un campo de acción moral.

En ese contexto, la relación con la tierra ha resultado un enclave de particulares resonancias y ha sido el tópos emblemático de la gesta poiética en tanto constitución de sí mismo y constitución de la propia vida como un espacio digno. Tal como refiere Michel Foucault a propósito de su interpretación de la obra jenofontea,

la existencia del propietario, si se ocupa como es debido de su dominio, es en principio buena por sí misma; constituye en todo caso un ejercicio de resistencia, un adiestramiento físico que es bueno para el cuerpo, su salud y su vigor; alienta también a la piedad al permitir hacer espléndidos sacrificios a los dioses; favorece las relaciones de amistad al dar ocasión de mostrarse generoso, de cumplir con largueza los deberes de hospitalidad y de prestar buenos servicios a sus conciudadanos. ${ }^{7}$ (FOUCAULT, 1993, p. 141)

\footnotetext{
${ }^{7}$ Trad. Martí Soler.
} 
Este es el perfil de hombre que Jenofonte propone y, en ese esquema ético-antropológico-político, el trabajo asociado a la virtud es un pilar de su constitución.

La tierra y las bondades que la misma ofrece representan el enclave por excelencia de la posibilidad de sostener la vida para el pequeño labrador beocio, seguramente propietario de una parcela de tierra, tal como parece ser el caso de Hesíodo. Al mismo tiempo, la tarea volcada sobre esa tierra fecunda es la posibilidad de un juego exhortativo y didáctico que pone a Hesíodo en el papel que le conocemos: persuadir de los beneficios del trabajo por encima de cualquier otra actividad que se le oponga.

Si pensamos en Jenofonte, podemos establecer algunos puntos de contacto con el esquema precedente, sobre todo en el lugar que ocupan el trabajo y la agricultura como formas de vida, ya que

el ideal de autarquía que defenderán en el siglo IV los filósofos en sus construcciones utópicas es la traducción de esta realidad: el hombre griego vivía en primer lugar del producto de su tierra, y el buen funcionamiento de la ciudad exigía que todos los que formaban parte de la comunidad cívica estuvieran dotados de ese producto. (MOSSÉ, 1993, p. 36)

Asimismo creemos ver en su obra el mismo matiz éticoantropológico, ya que está fuertemente abordada la relación entre el hombre y su trabajo como marca subjetivante y la relación del hombre con su êthos en tanto forma de vida. Sobrevuela el texto la misma preocupación hesiódica por el tipo de hombre que el trabajo como actitud de vida instituye. Por lo tanto apreciamos una dimensión similar que recupera una dimensión ético-antropológica donde lo que subyace es un modelo de hombre. Pensemos en la cita de Jenofonte:

Te he contado esto, Critobulo, continuó Sócrates, haciéndote ver que ni siquiera los muy afortunados pueden prescindir de la agricultura. Da la impresión, en efecto, que esta ocupación es al mismo tiempo un motivo de placer, un medio para acrecentar la hacienda y una forma de entrenar el cuerpo para poder hacer cuanto corresponde a un hombre libre. (Económico, $\mathrm{V}, 1)$ 
En primer lugar, se observa la capital importancia de la agricultura como medio de vida; no obstante, constituye algo más que eso ya que, más allá del placer, la prosperidad y el entrenamiento del cuerpo, resulta ser el medio de constitución del hombre libre. Ya en Hesíodo el trabajo en los campos había sido el medio de vida del hombre que aborrece el hambre y que prevé la posibilidad de acrecentar su patrimonio a través del mismo.

Al mismo tiempo, también en Hesíodo hay algo que roza la libertad porque no trabajar implica el pasaporte a depender de otro, con las consecuencias nefastas que ello supone en relación a los vínculos interpersonales que, tanto el trabajo como la ausencia del mismo, determinan.

Otro rasgo a tener en cuenta son las marcas dietéticas que el trabajo inscribe en el horizonte de preocupación. Creemos ver, tanto en Hesíodo como en Jenofonte, una preocupación por el cuerpo que anuda la propia relación del hombre con su cuerpo como fuerza de trabajo. Sabemos que el cuerpo representa el motor de la actividad laboral y por eso mismo entra en una cuadrícula de problematización para que su fuerza no decaiga. Las recomendaciones dietéticas de Hesíodo en relación al cuerpo y el ciclo estacional se inscriben en esa línea. El cuerpo es un bien preciado que debe ser cuidado y mantenido en forma, incluso para aumentar su rendimiento. ${ }^{8}$

En ambos autores se observa una altísima consideración sobre la tierra como productora de frutos. El largo apartado dedicado a Hesíodo nos ha permitido acompañar esa consideración a partir de las bondades de la tierra a lo largo del ciclo estacional y el orden que ello implica. Creemos que este orden puede inscribirse en lo que Mario Vegetti entiende por "sacro" cuando afirma: "Sacro es también, por tanto, el orden de la naturaleza, la sucesión de las estaciones, de las cosechas, del día y la noche" (VEGETTI, 1993, p. 296). ${ }^{9}$

\footnotetext{
${ }^{8}$ M. Foucault, (1993) en su obra Historia de la sexualidad: vol. II-el uso de los placeres, en el apartado de la dietética, primero en el orden del tratamiento que el autor hace, analiza las relaciones del hombre con su propio cuerpo como modo de recalar en un tópos privilegiado que da cuenta de la constitución de uno mimo como sujeto prudente. La relación con el cuerpo no puede permanecer ajena en los juegos de subjetivación porque el vínculo establecido da cuenta del dominio del hombre sobre sí mismo.

9 Trad. Antonio Bravo García.
} 
En Jenofonte asistimos a una misma consideración: "En primer lugar, en efecto, la tierra produce para quienes la trabajan los productos con los que viven los hombres y les concede además cuanto les permite vivir regaladamente" (Económico, V, 2-3). Independientemente de los avatares estacionales, la tierra es aquello que anuda la relación hombredignidad porque es la que permite, en última instancia, que el sazonado sustento no falte nunca del hogar del hombre trabajador. Esa es la mayor bondad que la tierra ofrece: alejar el oprobio del hambre y dignificar al hombre con el fruto regocijante de su trabajo.

Ahora bien, tanto en uno como en otro la tierra se muestra generosa pero no sin esfuerzo. El esfuerzo es un nuevo tópico que emparienta a ambos autores. Todo el proemio al trabajo da cuenta de esa exigencia. En Hesíodo han sido los propios dioses quienes han dispuesto el esfuerzo como condición misma del hombre. El esfuerzo sostenido en el tiempo es así una marca antropológica por excelencia que Jenofonte retoma en la misma dirección:

Y aunque la tierra concede sus bienes con la mayor abundancia, no permite que se recojan sin esfuerzo, sino que acostumbra a los hombres a soportar los fríos del invierno y los calores del verano. A los labriegos les aumenta la fuerza física ejercitando el vigor de sus brazos, y a los que trabajan como vigilantes les endurece despertándoles al amanecer y obligándoles a hacer duras caminatas. Pues tanto en el campo como en la ciudad, los asuntos más importantes tienen siempre fijada su hora. (Económico, $\mathrm{V}, 4-5)$

La cita abre un panorama rico en la tarea de comparación. Se observa en el pensador clásico una referencia al ciclo estacional, considerando los trabajos de las estaciones extremas, el frío y el calor, así como las relaciones que las estaciones guardan con los hombres, con su fortaleza y sus hábitos de vida. Un mismo telón de fondo se percibe en ambos a la hora de ajustar el cuerpo y el trabajo a las marcas de un ciclo estacional que regula la hora de cada labor. La relación estrecha entre el trabajo y el tiempo anuda una legalidad que repercute sobre la vida de los hombres. No se trata de una consideración del tiempo como un elemento complementario de la actividad, sino de una reflexión sobre su dimensión regulativa de la vida. La vida es un todo y el tiempo legisla sobre ese hólon, siendo el trabajo una manifestación de esa normatividad. 
Por eso cada actividad tiene su hora y su kairós. Este es un concepto clave, a nuestro entender, que hilvana la obra de ambos pensadores. La tierra, el esfuerzo, el trabajo constituyen el kairós de un modelo de subjetivación, de una manera de convertirse en un sujeto prudente, en un hombre cabal, en lo que en Jenofonte constituye un kalokagathós, un modelo de hombre de bien. Es el punto en que el trabajo se inscribe de un diagrama de subjetivación, constituyendo un ejercicio a través del cual los hombres buscan hacer de sí mismos sujetos virtuosos. ${ }^{10}$

Un nuevo aspecto de relación es la dimensión estatutaria que el trabajo abre. En Hesíodo podemos ver relaciones de mando y subordinación que se dan a partir de la relación que el trabajo implica. La compañía en la tarea de ciertos personajes, colaboradores y esclavos cuidadosamente seleccionados, que el poema propone, da cuenta de las relaciones interpersonales que la actividad supone. En Jenofonte se advierte un diagrama laboral semejante, siendo el tópico del mando una de las claves interpretativas de la obra de Jenofonte, ya que como sostiene C. Mossé, "el propietario de una finca extensa y de un solo terreno tenía que estar en posesión de un equipo de trabajadores de condición servil bajo las órdenes de un intendente, también él frecuentemente un esclavo" (MOSSÉ, 1993, p. 40). Es por esta complejidad de roles y estatutos que

la agricultura también enseña a mandar a los hombres; contra el enemigo, en efecto, hay que ir con hombres, y también con hombres se lleva a cabo la labranza de la tierra. Por ello, quien se disponga a ser un buen labrador necesita conseguir que sus obreros tengan buena voluntad y estén decididos a obedecerle. (Económico, V, 14-15)

El texto es muy elocuente. En ambos autores se observa una preocupación por la elección de quienes habrán de acompañar la tarea, fundamentalmente porque sabemos que ella implica la clave de la sustentabilidad de la vida. En Hesíodo aparecen referencias a la edad y

\footnotetext{
${ }^{10}$ Sobrevuela esta idea los estudios de Michel Foucault en torno a las prácticas sensatas y voluntarias por las cuales los hombres buscan hacer de su vida una obra de arte, tal como sostiene en Historia de la sexualidad; a partir del télos de una vida conforme a ciertos principios de lo bello y de lo bueno, los hombres temperantes buscan intensamente transformarse a sí mismos para convertirse en otra cosa de lo que son. El trabajo asociado a la virtud, se inscribe, a nuestro entender, en esas prácticas de sí (COLOMBANI, 2009 - Apartado III, Políticas del alma).
} 
al vigor de aquellos que llevan a cabo ciertas tareas, tal como la cita de Jenofonte refiere. Por otra parte, el trabajo implica en sí mismo un juego de jerarquías estatutarias donde alguno debe ser quien manda y conduce la actividad y a otros les corresponde ser mandados. En ese sentido el trabajo enseña a mandar, a ejercer la autoridad sobre otros, a sostener una posición de autoridad que, en el caso de Jenofonte, tiene distintos tópoi donde ese juego jerárquico se refleja, entre ellos, por supuesto, el ôk os. Se trata de territorios emblemáticos donde el ejercicio del varón como administrador de un cierto espacio de poder constituye un núcleo de problematización fuerte. La agricultura y el hogar resultan así espacios isomórficos, en la medida en que un mismo patrón de conducción debe atravesarlos para optimizar su rendimiento. El tema es político, se trata del espinoso tema del dominio, del poder que se ejerce sobre otros, sean los esclavos o la mujer, los hijos o los intendentes o mayordomos. Siempre el principio de problematización es el ejercicio de un poder que ubica al varón prudente en un lugar de mando y autoridad. Tal como sostiene Michel Foucault leyendo la condición del hombre casado presente en el Económico, "pero ser casado significa aquí ante todo ser jefe de familia, tener una autoridad, ejercer un poder que tiene en la 'casa' su lugar de aplicación y sostener las obligaciones respectivas que inciden sobre su reputación de ciudadano" (FOUCAULT, 1993, p. 139). Más allá de la puntualidad de la referencia al matrimonio, la condición de "jefe" es extensiva a las cuestiones económicas como aquellas que hacen a la totalidad de la vida del varón libre. Se trata siempre de las ventajas personales y cívicas de la existencia de un hombre prudente que han de confluir “en lo que aparece como el mérito principal del arte 'económico': aprender la práctica del mando que es indisociable. Dirigir el ô̂kos es mandar y mandar en la casa no es distinto del poder que debe ejercerse en la ciudad" (FOUCAULT, 1993, p. 141).

Retornando a la letra del texto, la agricultura aparece como una actividad de relevancia absoluta, tal como pudimos observar en la consideración del poema hesiódico respecto del tópico:

Estuvo muy acertado el que dijo que la agricultura era la madre y la nodriza de las demás artes, pues si la agricultura florece, prosperan también las otras artes, pero cuando la tierra se ve obligada a mantenerse yerma, se marchitan casi sin excepción las restantes artes, tanto en la tierra como en el mar. (Económico, V, 17) 
La agricultura aparece como una actividad rectora porque las distintas situaciones que su condición devuelve determinan la situación de los hombres sobre la tierra. En efecto, la fecundidad y la prosperidad que la tierra dona generan particulares condiciones de vida que se desdibujan cuando su condición es otra. El tema se inscribe en la tensión fecundidadaridez como condiciones posibles. En un marco semejante, cuando Hesíodo pinta las características de la ciudad sana y de la ciudad enferma, la agricultura aparece con la misma actitud rectora y dominante. La ciudad sana se ve favorecida por las bondades de la tierra que dispensa sus frutos por doquier, mientras la enferma conoce el hambre porque la tierra no produce el sazonado sustento y el hambre se enseñorea en los hogares.

En Hesíodo el trabajo tiene un telón de fondo religioso que hace de la actividad un ejercicio que se inscribe en el marco de la religiosidad que impregna su obra. Un matiz semejante creemos advertir en Jenofonte cuando sitúa el trabajo en un plano afín:

En cuanto a las faenas agrícolas, ¿te imaginas que es menos necesario propiciarse a las divinidades? Porque has de saber que los hombres sensatos ofrecen plegarias a los dioses por la protección de los frutos y del grano, de los bueyes, los caballos, las ovejas y todas sus propiedades. (Económico, V, 20)

El texto es, una vez más, elocuente. Los dioses están por encima de cualquier actividad de los mortales porque se hallan, en última instancia, por sobre los hombres en su conjunto (GERNET, 1981). El vínculo entre estas esferas que, como sabemos, se distancian ontológicamente, es el sacrificio y Jenofonte lo reclama como protección de la tarea. Jenofonte está incluyendo la piedad en el repertorio de cualidades que un hombre de bien debe tener y, en ese aspecto, Hesíodo constituye un antecedente, ya que la constitución del varón prudente se apoya sobre el trabajo, la virtud y la piedad como tópicos incuestionables. Incontables son los versos que en Trabajos y Días dan cuenta de esta necesaria observancia de los dioses como aquellos que rigen el campo humano. Es esta relación del hombre con el plano religioso del mundo a lo que L. Gernet denomina "antropología"11 (GERNET, 1981, p. 13).

${ }^{11}$ Trad. Bernardo Moreno Carrillo. 
Tanto en Jenofonte como en Hesíodo estamos en presencia de un saber asociado a un poder. Si bien en Jenofonte se sistematiza de algún modo ese saber sobre el trabajo de la tierra, no es menos cierta la presencia de un saber sobre el trabajo en Hesíodo. El apartado que le hemos dedicado se refiere precisamente a una experiencia sometida a un saber que, además, se puede enseñar, tal como de ello dan cuenta los consejos que engrosan su poesía didáctica. En Jenofonte el tema toma cuerpo de preocupación epistémica y sobrevuela la intención de articular un verdadero saber en el arte de conducir:

- Desde luego, dijo Sócrates, la administración de la hacienda nos pareció que era el nombre de un saber, y este saber resultó ser el que hace que los hombres puedan acrecentar su hacienda; hacienda nos pareció ser lo mismo que la totalidad de las propiedades, y, a su vez, afirmamos que propiedad era lo provechoso para la vida de cada uno, y provechoso se descubrió que era todo aquello de lo que se supiera hacer uso. (Económico, VI, 4-5)

En Hesíodo está presente, a nuestro criterio, una preocupación semejante en torno a la descripción de un saber empírico que tiene al cultivo como protagonista. Un saber que determina un cierto poder. Poder sobre el objeto que se manipula o sobre el que recae la actividad y que genera efectos sobre la vida en su conjunto. Saber cultivar la tierra y administrar los recursos naturales y humanos que la labor agrícola implica, aportan un beneficio que tiñe la vida como un todo:

Porque la tierra no exhibe nada para engañar, sino que revela simplemente y con veracidad lo que puede y lo que no puede producir. Yo creo que la tierra, por el hecho de ponerlo todo al alcance de nuestro conocimiento y facilidad de comprensión, es la mejor piedra de toque para distinguir a los buenos y a los malos. En efecto, a diferencia de las demás artes, los que no la practican no pueden poner como pretexto su ignorancia: todos saben que la tierra devuelve favor por favor. La desidia en la agricultura es una clara acusadora de un espíritu mentiroso: nadie podría convencerse a sí mismo de que puede vivir sin lo necesario; si un hombre no conoce ningún oficio lucrativo ni está dispuesto a ser labrador, es evidente que o se propone vivir del robo, la rapiña o la mendicidad, o está completamente loco. (Económico, XX, 13-16) 
He aquí el meollo de la relación entre trabajo y virtud. El trabajo resulta así una bisagra territorializante para diferenciar aquellos que lo abrazan, como motor de vida, de aquellos que lo desdeñan.

También en el poeta beocio el trabajo está íntimamente asociado a la virtud hasta constituir las dos caras de una misma moneda. Es el propio trabajo la bisagra que especializa a los mortales en el campo del trabajo-virtud o en la zona de la pereza y la falta de excelencia. Perses es el más claro ejemplo de quien desconoce las virtudes de la tierra y sus posibilidades de entrega. El robo, la rapiña o la mendicidad son las marcas de un tiempo signado por la injusticia que Hesíodo denuncia en actitud moralizante.

El aparatado dedicado a Hesíodo ha resultado una verdadera lección del maridaje entre la agricultura y el ciclo estacional, tal como hemos sostenido en distintas oportunidades. Queremos recuperar esa preocupación dominante en el poeta beocio para pensar la misma preocupación en Jenofonte cuando, a través de una serie de interrogantes, da cuenta de la problematización:

“¿Por dónde quieres, Sócrates, que empiece a refrescarte la memoria sobre la agricultura? Porque sé que voy a decirte muchas cosas que tú ya sabes sobre la manera de trabajar la tierra". "En primer lugar, Iscómaco", le respondí, "creo que me gustaría aprender (porque es lo más propio de un filósofo) cómo tendría que cultivar la tierra si quisiera obtener la mayor cosecha de cebada y trigo". (Económico, XVI, 8-11)

Sobre este presupuesto inicial, una serie de cuestiones entran en el juego dialógico reforzando la misma preocupación que el lógos didáctico de Hesíodo supiera devolvernos. La preparación del barbecho, la inconveniencia de arar la tierra en invierno porque sería un barrizal. La misma inconveniencia de hacer el barbecho en verano porque la tierra está muy dura para moverla con el arado. Finalmente el momento oportuno de iniciar la tarea es en primavera. Apenas un par de cuestiones para hacer visible una misma inquietud devenida en una verdadera cultura agraria. La misma relación establecida por Hesíodo entre trabajo y kairós.

Una referencia a los antepasados sea quizás la mejor corroboración del trazo de lectura que estamos proponiendo: 


\begin{abstract}
Y en cuanto a la época de la siembra, Sócrates, ¿te das cuenta que el momento de sembrar no es otro que el que nuestros antepasados primero, por haberlo comprobado, y todos nosotros ahora, por estar haciendo prueba, consideramos el más oportuno? Porque cada vez que llega la estación del otoño, todos los hombres dirigen su mirada a la divinidad para ver cuándo les permitirá sembrar, enviándoles la lluvia. (Económico, XVII, 1-2)
\end{abstract}

La referencia a los antepasados habla de un saber que se construye anclado en la tradición y en la experiencia compartida, más allá del tiempo que separa a los hombres. Hay un oficio vivo que supone algún modo de transmisión, a partir de la instalación en la tierra como modo de vida, a partir de su vital importancia para la vida de los hombres. El apartado del Económico es abundante en un juego de preguntas y respuestas a través de las cuales Sócrates e Iscómaco debaten sobre los asuntos agrarios.

Las marcas de la conversación se asemejan muchísimo a las preocupaciones y exhortaciones que Hesíodo considera en el proemio al trabajo. Se trata también de un verdadero manual de agricultura que toma la forma de un juego de preguntas y respuestas a través de las cuales se está enseñando, en última instancia, un oficio. Más allá de la puntualidad del tema, el objetivo del discurso constituye un nuevo punto de contacto. No porque el estilo en sí sea similar, sino porque el lógos está al servicio de una dimensión didáctica. Enseñar el arte de la agricultura es, al mismo tiempo, enseñar un modelo de gestión, que, en el caso concreto de Jenofonte, constituye una enseñanza que abraza a los ciudadanos como núcleo de preocupación política.

\title{
2 Conclusiones
}

También llegamos a la conclusión de que para el hombre de bien la agricultura es la actividad y el saber más importante, ya que de ella se procuran los hombres el sustento. Y esta actividad nos pareció la más fácil de aprender y la más agradable de practicar, la que mantenía los cuerpos más sanos y robustos y la que más ocio dejaba al espíritu para dedicarse a los amigos y a la ciudad. (Económico, VI, 8-9) 
La elección de la cita es deliberada para afrontar la conclusión del presente trabajo porque abarca los tópicos dominantes que han constituido nuestro objeto de preocupación. La agricultura como base del trabajo que, a su vez, constituye la mayor dignidad para el hombre, es un saber enseñable que entraña, asimismo, una forma de poder. El poder que significa vivir del propio trabajo y no depender del otro como gesto de dependencia; a su vez, se trata del poder de constituirse a uno mismo como sujeto virtuoso, asociando la ecuación trabajo-virtud como modo de vida. He aquí la posibilidad de efectuar una lectura ético-antropológica en ambos autores, porque lo que está en el centro de la discusión es la constitución del varón prudente y de su manera de vivir.

En segundo lugar, aparece la más elemental necesidad humana: obtener el sustento. A partir de esta satisfacción básica, fuerte preocupación hesiódica por el escenario que el hambre conlleva, la perspectiva posterior abre el panorama económico presente en ambos autores aunque con matices diferentes. La aldea hesiódica dista mucho de constituir el hábitat de la ciudad del Jenofonte. La principal preocupación de Hesíodo es lograr el sazonado sustento para que el hambre no roce a los mortales. Su acumulación puede traer algún bienestar y un claro signo de previsión que habla del hombre prudente.

En Jenofonte estamos en presencia de otra cosa que arranca, no obstante, en la misma necesidad de satisfacción humana. La agricultura representa una base de marcada proyección económica, junto a otras actividades fuertemente vinculadas a la obtención de ganancias y acumulación de riquezas.

En tercer lugar, la referencia a las características de la actividad misma da cuenta de un involucramiento del cuerpo que roza cuestiones dietéticas en tanto cuidado del mismo como fuerza de trabajo. Una vez más este tipo de cuidados alcanza la constitución de uno mismo como hombre prudente, como forma del gobierno de sí. Cuidar el cuerpo de trabajo es siempre cuidar un bien preciado que la naturaleza le ha brindado al hombre para ser administrado como es debido.

Nos ha movido el propósito de establecer las líneas de continuidad entre Hesíodo y Jenofonte, con las reservas que ello implica, pero reconociendo en el poeta de Ascra elementos que preanuncian el ulterior pensamiento clásico. En este suelo, el poeta se inscribe en un tipo de cosmovisión que continúa dominando en Grecia, tal como sostiene J. C. Rowe (1983, p. 135) cuando problematiza su ubicación en el marco 
de la primera filosofía, recomendando, no obstante, la precaución en su inclusión y el análisis cuidadoso de los tópicos que se priorizan, para pensarlo desde ese andarivel pre-filosófico.

\section{Referencias bibliográficas}

\section{Fuentes}

HESÍODO. Obras y fragmentos. Aurelio Pérez Jiménez (prologuista) y Alfonso Martínez Díez (traductor). Madrid: Gredos, 2000.

HESIOD. Theogony; Works and Days; Testimonia. Edited and transl. by G. W. Most. Cambridge Mass.: Harvard University Press, 2006.

JENOFONTE. Recuerdos de Sócrates; Económico; Banquete; Apología de Sócrates. Introducciones, trad. y notas de Juan Zaragoza. Madrid: Gredos, 1993.

LIDDEL, H. G.; SCOTT, R. A Greek-English Lexicon. Oxford: Clarendon Press, 1996.

LIÑARES, L. Hesiodo: Teogonía, Trabajos y Días. Edición bilingüe. Buenos Aires: Losada, 2005.

VIANELLO DE CÓRDOVA, P. Hesiodo: Teogonía. México: Universidad Nacional Autónoma de México, 1978.

\section{Bibliografía secundaria}

COLOMBANI, M. C. Foucault y lo político. Buenos Aires: Prometeo, 2009.

FOUCAULT, M. Historia de la locura en la época clásica. Trad. Juan José Utrilla. México: Fondo de Cultura Económica, 1990.

FOUCAULT, M. Historia de la sexualidad: vol. 2 - el uso de los placeres. Trad. Martí Soler. México: Siglo XXI, 1993.

GERNET, L. Antropología de la Grecia Antigua. Trad. Bernardo Moreno. Madrid: Taurus, 1981. 
JUDET DE LA COMBE, P.; LERNOULD, A. Sur la Pandore des Travaux: esquisses. In: BLAISE, F.; JUDET DE LA COMBE, P.; ROUSSEAU, P. (org.). Le métier du mythe: lectures d'Hésiode. Lille: Presses Universitaires du Septentrion, 1996, p. 301-313.

MOSSÉ, C. El hombre y la economía. In: VERNANT, J.-P. (org.). El hombre griego. Versión española de Pedro Bádenas de la Peña (introducción, cap. I, II y III), Antonio Bravo García (cap. VI, VII y VIII) y José Antonio Ochoa Anadón (cap. IV, V y IX). Madrid: Alianza, 1993, p. 35-63.

NELSON, S. The drama of Hesiod's farm. Classical Philology, Chicago, vol. 91, n. 1, p. 45-53, enero 1996.

NESCHKE, A. Dikè: la philosophie poétique du droit dans le "mythe des races" d' Hésiode. In: BLAISE, F.; JUDET DE LA COMBE, P.; ROUSSEAU, P. (org.). Le métier du mythe: lectures d'Hésiode. Lille: Presses Universitaires du Septentrion, 1993, p. 465-478.

ROWE, C. J. 'Archaic Thought' in Hesiod. The Journal of Hellenic Studies, Cambridge, vol. 103, p. 124-135, 1983.

VEGETTI, M. "El hombre y los dioses". In: VERNANT, J.-P. (org.), El hombre griego. Versión española de Pedro Bádenas de la Peña (introducción, cap. I, II y III), Antonio Bravo García (cap. VI, VII y VIII) y José Antonio Ochoa Anadón (cap. IV, V y IX). Madrid: Alianza, 1993, p. 289-321. 